\title{
Effect of Modification Methods of Wheat Straw Fibers on Water Absorbency and Mechanical Properties of Wheat Straw Fiber Cement-Based Composites
}

\author{
Demin Jiang $\mathbb{D}^{1}{ }^{1}$ Penghui An, ${ }^{1}$ Suiping Cui, ${ }^{2}$ Shiguo Sun, ${ }^{1}$ Jingzong Zhang, \\ and Tianfu Tuo ${ }^{1}$ \\ ${ }^{1}$ College of Civil Engineering, North China University of Technology, Beijing 100144, China \\ ${ }^{2}$ College of Materials Science \& Engineering, Beijing University of Technology, Beijing 100124, China \\ Correspondence should be addressed to Demin Jiang; jdm2004@126.com
}

Received 8 November 2019; Accepted 11 January 2020; Published 7 February 2020

Academic Editor: Francisco Javier Fernández Fernández

Copyright (C) 2020 Demin Jiang et al. This is an open access article distributed under the Creative Commons Attribution License, which permits unrestricted use, distribution, and reproduction in any medium, provided the original work is properly cited.

\begin{abstract}
Five modification methods are adopted for wheat straw fibers (WSFs). The effects of modification methods on the water absorbency of wheat straw fiber/wheat straw fiber cement-based composite (WSFCC) and the mechanical properties of WSFCC are analyzed. The crystallinity, chemical structure, and micromorphology of WSFs and WSFCC 28-day specimens are characterized by XRD, FTIR, and SEM methods. The results show that the water absorption of WSFs modified with sodium silicate solution, pure acrylic acid emulsion, and silicone waterproof emulsion surface spraying is $10.67 \%, 5.18 \%$, and $1.05 \%$ lower than that of unmodified WSFs, respectively. Alkali modification is the ideal method for improving the strength of WSFCC. Establishing a fitting formula of the relationship between water absorption of WSFs and strength of WSFCC specimens has important theoretical and practical guiding significance for development and application of WSFCC.
\end{abstract}

\section{Introduction}

The annual output of straw around the world has surpassed 2.9 billion tons. Of the 2.9 billion tons, $66 \%$ is returned directly to the field or incinerated as living energy, $19 \%$ for building materials or vegetable production covering materials, $12 \%$ as forage for herbivorous livestock, and $3 \%$ as raw materials for handicraft making [1-3]. Waste straw is a pollutant and contributor to climate change. There are three major types of crop straw in China: rice, wheat, and corn. Combined, they can reach more than 450 million tons annually $[4,5]$. About $30 \%$ of the crop straw is discarded every year in China. These unused straws are burned in the field or burned away. Straw incineration in open air not only wastes valuable renewable natural resources but also causes environmental pollution and poses great threats to traffic safety of highways, railways, and civil aviation flights and causes serious harm to human health and safety. It has become a major social problem $[6,7]$. Therefore, it has become an urgent task for the scientific researchers in China and the world to speed up the comprehensive utilization of straw resources and realize the commercialization and recycling of straw to improve the atmospheric environment.

It can be an effective way of using crop straw resources to use them to prepare plant fiber cement-based composites and make it possible for the plant fiber cement-based composites to be widely applied in the construction sector, especially in the sectors that have a large demand for thermal insulating wall materials [8-10]. And how to make full use of the lightweight, porous, thermal insulation, sound insulation, and other characteristics of plant fibers in building materials is the starting point of this effective way. Ren et al. [11] developed a new type of straw block with wheat straw fiber, sand, and cement as raw materials and applied it to the wall of solar greenhouse. The research shows that the thermal-wet and bacteriostatic properties of the new type of straw block are better than those of porous clay block. Bederina et al. [12] used hot water, gasoline, varnish, and 
waste oil to treat barley straw to improve the performance of lightweight composite concrete. The results show that the four treatments can significantly improve the tensile strength of barley straw. The straw treated with hot water, gasoline, varnish, and waste oil has positive effects on improving the flexural strength, less shrinkage, and density of concrete. Hou et al. [13] studied the heat-moisture coupling transmission of hollow concrete blocks filled with compressed straw bricks. The results show that filling compressed straw bricks into hollow concrete block can hinder heat transfer and improve moisture buffering performance of multilayer wall.

There are still a series of problems in the process of compounding straw fibers with cement-based materials. The biggest problem is still the poor compatibility between plant fibers and cement-based materials. It is a bottleneck affecting the popularization and application of plant fiber cementbased composites at home and abroad [14, 15]. Plant fibers with higher water absorbency will have an adverse effect on cement-based composites. There are numerous polar hydroxyl groups in plant fibers, which enable plant fibers to have high water absorbency. The plant fibers with higher water absorbency will cause problems with the physical and mechanical properties of plant fibers cement-based composites [16-19] for the following reasons. (a) During the molding process of plant fiber cement-based composites products, plant fibers with high water absorption are likely to agglomerate so as to make plant fiber cement-based composites mixture difficult to mix evenly. This would affect not only the workability of mixture but also the performance of hardened plant fiber cement-based composites. For plant fiber cementbased composites mixture reaching the same consistency, the amount of water for mixing increases. The excessive water evaporates or stays in concrete, forming capillary holes, pores or bubbles, which reduces the effective section of hardened plant fiber cement-based composites and tends to produce stress concentration around these pores. (b) Plant fibers with high water absorption are easy to inhale alkali solution in the alkaline environment of cement hydration and cause corrosion damage, which leads to the decrease or even loss of the original properties of plant fibers. In addition, during the process of absorbed water release, the sugar components in plant fiber extracts block hydration and hardening of cement [20]. (c) Plant fibers with high water absorption also have a problem of dry shrinkage and wet expansion leading to volume change of plant fibers, affecting the bond strength between fibers and cement-based materials and reducing the reinforcing, toughening, and anticracking of fibers.

Current literature on cement-based composites is incomplete [21, 22]. Existing studies about plant fiber cementbased composites have mainly focused on the reinforcement and anticracking action of plant fibers. Little attention has been paid to the water absorbency of plant fibers and the mechanism of reducing water absorbency of plant fibers. In this paper, the WSFs (wheat straw fibers) are modified with various modification materials and techniques. The modifications are based on previous studies [23-25] and applied to Chinese high yield WSFs. The effects of different modification methods on water absorbency of WSFs and water absorbency and mechanical properties of wheat straw fiber cement-based composites (WSFCCs) are studied. The degree of crystallization, chemical compositions, and microstructure of WSFs before and after modifications are characterized by the X-ray diffractometer (XRD), Fourier-transform infrared spectrometer (FTIR), and scanning electron microscope (SEM). The influence mechanism of modification methods of WSFs on water absorbency and mechanical properties of WSFCC is clarified. Finally, the fitting relationship between water absorption of WSF and strength of WSFCC is established. The results of the study shall provide a theoretical and scientific basis for optimizing the compatibility between WSFs and WSFCC and effectively promoting the comprehensive utilization of crop stalks all over the world.

\section{Materials and Methods}

\subsection{Materials}

2.1.1. Cement. Strength grade $42.5 \mathrm{MPa}$ common Portland cement of Diamond Brand was manufactured by Yanjiao New Building Materials Inc., Sanhe city, Hebei Province. The chemical compositions of cement and mineral admixtures are shown in Table 1.

2.1.2. Fly Ash. Class II fly ash was purchased from Beijing Shijingshan Power Plant. And its performance fulfills the requirements of Chinese national standard GB/T 501462014 Technical Code for Application of Fly Ash Concrete. Its chemical compositions are shown in Table 1.

2.1.3. Wheat Straw. Wheat straw was purchased from Ailun Shipping Services Co., Ltd., Rizhao city, Shandong Province. Wheat straw was processed into fibers by drying, crushing, and sieving. The $0.15-0.3 \mathrm{~mm}$ fibers are used as raw material for testing [25]. The appearances of wheat straw and WSFs are shown in Figure 1. The bulk density and apparent density of WSFs are $0.13 \mathrm{~g} / \mathrm{cm}^{3}$ and $0.17 \mathrm{~g} / \mathrm{cm}^{3}$, respectively. The chemical compositions of WSFs are shown in Table 2.

2.1.4. Sodium Silicate $\left(\mathrm{Na}_{2} \mathrm{O} \cdot n \mathrm{SiO}_{2}\right)$ Solution. Sodium silicate solution was manufactured by Beijing Yongfei Adhesive Factory; it has a modulus of 3.1 , Baume $40^{\circ}$, a density of $1.38 \mathrm{~g} / \mathrm{cm}^{3}$, and a content of total solids $36.20 \%$.

2.1.5. Pure Acrylic Polymer Emulsion. The PRIMAL MAC$261 \mathrm{P}$ acrylic polymer emulsion produced by American Rohm \& Haas company has a solid content of 50\%, a density of $1.04 \mathrm{~g} / \mathrm{cm}^{3}$, and a $\mathrm{pH}$ of 8.8 . Silicone waterproof emulsion: IE-6683 waterproof emulsion developed by American Dow Corning Company is used. Its content of alkoxysilane and polydimethylsiloxane active material is $40 \%$, density is $1.01 \mathrm{~g} / \mathrm{cm}^{3}$, and $\mathrm{pH}$ is $6-8$.

2.1.6. Sodium Hydroxide $(\mathrm{NaOH})$. Sodium hydroxide was purchased from Beijing Chemical Plant, AR; it has a content of major ingredients $\geq 96.0 \%$. 
TABle 1: Chemical composition of cement and mineral admixture (wt.\%).

\begin{tabular}{lccccccccc}
\hline Type of materials & $\mathrm{CaO}$ & $\mathrm{SiO}_{2}$ & $\mathrm{Al}_{2} \mathrm{O}_{3}$ & $\mathrm{Fe}_{2} \mathrm{O}_{3}$ & $\mathrm{TiO}_{2}$ & $\mathrm{MgO}$ & $\mathrm{SO}_{3}$ & $\mathrm{Na}_{2} \mathrm{O}$ & Ignition loss \\
\hline Cement & 62.38 & 25.52 & 6.15 & 3.27 & 0.57 & 1.54 & 1.65 & 0.21 & 2.87 \\
Fly ash & 1.93 & 54.88 & 32.12 & 4.28 & - & 1.45 & 1.46 & - & 3.82 \\
\hline
\end{tabular}

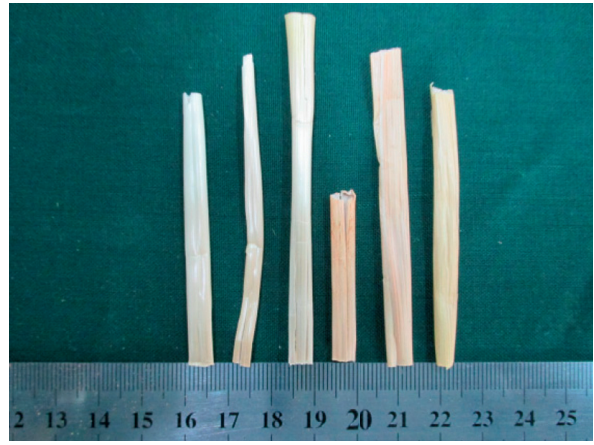

(a)

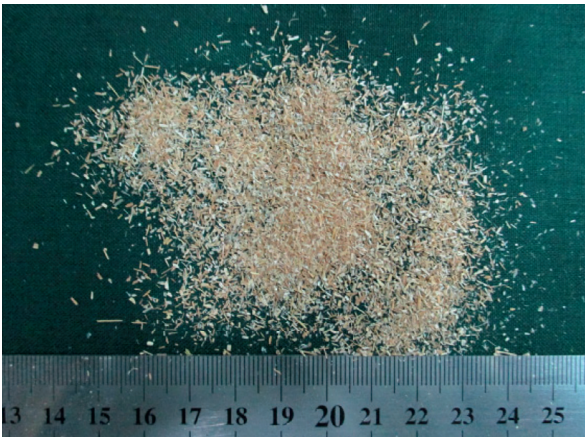

(b)

FIgURE 1: Appearance of wheat straw and wheat straw fiber. (a)Wheat straw. (b) Wheat straw fiber (particle size $0.3 \mathrm{~mm}$ ).

TABle 2: Chemical composition of wheat straw fibers (wt.\%).

\begin{tabular}{|c|c|c|c|c|c|c|c|c|c|c|c|}
\hline \multirow[b]{2}{*}{ Item } & \multirow[b]{2}{*}{$\begin{array}{c}\text { Moisture } \\
\text { content }\end{array}$} & \multirow[b]{2}{*}{$\begin{array}{c}\text { Ash } \\
\text { content }\end{array}$} & \multirow[b]{2}{*}{ Holocellulose } & \multirow[b]{2}{*}{ Cellulose } & \multirow[b]{2}{*}{ Pentosan } & \multirow[b]{2}{*}{ Lignin } & \multirow[b]{2}{*}{ Pectin } & \multicolumn{4}{|c|}{ Extracts of different solutions } \\
\hline & & & & & & & & $\begin{array}{c}\text { Hot } \\
\text { water }\end{array}$ & $\begin{array}{l}\text { Cold } \\
\text { water }\end{array}$ & $\begin{array}{l}\text { Alcohol } \\
\text { benzene }\end{array}$ & $\begin{array}{c}1 \% \\
\mathrm{NaOH}\end{array}$ \\
\hline $\begin{array}{l}\text { Wheat } \\
\text { straw }\end{array}$ & 4.69 & 11.19 & 66.68 & 42.10 & 22.41 & 17.53 & 0.31 & 16.85 & 14.32 & 11.23 & 58.97 \\
\hline
\end{tabular}

Note. Measuring was based upon the detection methods of GB/T2677 regarding the relevant ingredients of paper-making raw materials. Holocellulose refers to the total amounts of cellulose and hemicellulose in plant fiber raw materials.

2.1.7. Water. Drinking water fulfilled the Chinese National Standards; its $\mathrm{pH}=6.91$ at $25^{\circ} \mathrm{C}$.

\subsection{Methods}

2.2.1. Modification of WSFs. Physical and chemical methods are used to modify the WSFs. The physical method is to spray three kinds of modifiers onto the surface of WSFs to form a thin coat of corresponding modifying substances. The modifiers are diluted sodium silicate solution $\left(\mathrm{Na}_{2} \mathrm{O} \cdot \mathrm{nSiO}\right)_{2}$, acrylic polymer emulsion, and silicone waterproof emulsion. Spraying is performed in such a way that emulsion is dampened without any overflow. After spraying, WSFs are transferred into an electric blast oven and heated at $85 \pm 1^{\circ} \mathrm{C}$ for 24-30 h until drying completely, cooled to room temperature, and then stored in sealed plastic bags for later usage. The chemical methods are dipping WSFs into two kinds of modifiers, which are $\mathrm{NaOH}$ solution with a mass density of $3 \%$ and water, respectively, at room temperature. The dipping time of $\mathrm{NaOH}$ solution is $4 \mathrm{~h}$ and water $10 \mathrm{~h}$. Then, WSFs are rinsed with water for 5-7 times until squeezed fluid changes from brown to clear water. After drying in an electric air-blowing drying oven at $85 \pm 1{ }^{\circ} \mathrm{C}$ for 24-30 h, the samples are cooled to room temperature and stored in sealed plastic bags for later usage.
2.2.2. Water Absorption Test of WSFs. Based upon the method of light aggregate concrete as specified in JGJ 51-2002, $5 \mathrm{~g}$ WSF sample is placed into a square-hole sieve with hole size of $0.08 \mathrm{~mm}$. Then, the loaded sieve is immersed into a basin; water surface must not exceed the height of sieve frame. According to a certain time interval (measured every hour before 6 hours and extended appropriately after 6 hours), the square-hole sieve is taken out of basin to wipe its bottom and frame with a wrung wet towel and absorb the moisture on the surface of the fiber in the sieve. Then, WSFs are weighed with an electronic scale and mass water absorption of fiber calculated according to the below formula (1). The average water absorption within $24 \mathrm{~h}$ is taken as water absorption index.

$$
w_{t}=\frac{m_{t}-m_{0}}{m_{0}} \times 100 \%,
$$

where $w_{t}$ is the water absorption (\%) of the sample when the immersion time is $\mathrm{t}, m_{t}$ is the mass $(\mathrm{g})$ of the sample when the immersion time is $\mathrm{t}$, and $m_{0}$ is the mass ( $\mathrm{g}$ ) of the sample when dried to constant weight before the immersion.

2.2.3. Crystallinity Analysis of WSFs. A Shimadzu XRD$7000 \mathrm{X}$-ray diffractometer (XRD) is utilized with a working voltage of $40 \mathrm{kV}$ and a working current of $30 \mathrm{~mA}$. Continuous scanning is performed with a scanning range of 10 to 
80 degrees, a length of 0.02 degrees/step, and a speed of 2 degrees/min. PMGR software is utilized for data collection and Jade 5.0 for data analyzing and processing. The crystallinity (CI) of WSFs is expressed by relative crystallinity proposed by Zhou et al. $[10,14]$. The higher the degree of CI, the greater the degree of crystallization for natural cellulose. The formula for calculating CI is provided below:

$$
\mathrm{CI}=\frac{I_{002}-I_{\mathrm{am}}}{I_{002}} \times 100 \% \text {, }
$$

where $I_{002}$-maximal diffraction intensity of 002 plane and $I_{\mathrm{am}}$-diffraction intensity of $2 \theta \approx 18^{\circ}$, i.e., diffraction intensity of amorphous region.

2.2.4. Molecular Structure Analysis of WSFs. Manufactured by German Bruker Inc, Tensor 27 Fourier-transform infrared spectrometer (FTIR) is utilized. For each sample, the scanning wave numbers range from $400 \mathrm{~cm}^{-1}$ to $4000 \mathrm{~cm}^{-1}$, the scanning times are 32 , and the resolution is $4 \mathrm{~cm}^{-1}$. The samples are prepared by the $\mathrm{KBr}$ pressing method.

2.2.5. Microscopic Morphology Analysis of WSFs and WSFCC. The microstructure of WSFs and WSFCC are observed by ZEISS SIGMA FE-SEMs for high quality imaging and advanced analytical microscopy. When WSFs are observed, the test voltage is $2 \mathrm{kV}$. Prior to observations, the specimens are dried at $75^{\circ} \mathrm{C}$ and treated for 30 seconds with gold spray. When WSFCC is observed, the test voltage is $5 \mathrm{kV}$. WSFCC specimens are 28-day-old samples which are the same as those in the water absorption test (Section 2.2.6). Prior to testing, the specimens are dried at $85^{\circ} \mathrm{C}$, squashed into $2 \mathrm{~mm}$ cubes, and sprayed for $30 \mathrm{~s}$.

2.2.6. Water Absorption Test of WSFCC. It is performed in accordance with GB/T17671-1999 Method of Testing Cements-Determination of Strength (ISO Method). The consistency test of mixture is performed according to the GB/ T1346-2011 Testing Methods for Water Requirement of Normal Consistency, Setting Time, and Soundness of Portland Cements. The consistency of mixture is controlled at $30 \pm 3 \mathrm{~mm}$ while mixing and water consumption are adjusted according to the consistency value. Proportion (mass ratio): cement : fly ash : straw fibers : water $=1: 0.11$ : 0 . 17:0.54. The specimen size is of $40 \mathrm{~mm} \times$ $40 \mathrm{~mm} \times 160 \mathrm{~mm}$. After 7 days of standard curing, the specimens are immediately placed indoors $\left(20 \pm 5^{\circ} \mathrm{C}\right.$, $\mathrm{RH} \geq 50 \%)$ and cured to 28 days of age. The specimens are dried to constant weight at $85 \pm 1^{\circ} \mathrm{C}$ and weighed. Then, the specimens are put into the water tank. The gap between the specimens should be at least $5 \mathrm{~mm}$. The water level is about $2 \mathrm{~cm}$ above the surface of the specimens. The specimens are taken out of the water tank at a certain time interval, and the surface moisture of the specimens is wiped off with a wrung wet towel. After weighing, the specimens are put back into the water tank, and the water absorption rate of the specimens changed with time within 48 hours is measured. The average water absorption of triplicate specimens is taken as water absorption for each group, and the water absorption is calculated by the same formula (1).

2.2.7. Mechanical Property Test of WSFCC. The same specimen as the water absorption test (Section 2.2.6) is used for the mechanical performance test of WSFCC. A $300 \mathrm{kN}$ electronic universal testing machine (CDT305, Shenzhen, China) is utilized for testing the flexural and compressive strength of specimens. A group of triplicate specimens is taken out of each type of WSFCC at each age for strength test. Each group of specimens is initially subjected to a flexural test of three test pieces, and six broken blocks after the flexural test are used for a compressive strength test.

\section{Results and Discussion}

In order to express the experiment conveniently, the processing methods of WSFs and the performance tests of WSFs and WSFCC are sorted and coded. The meaning of test serial number and test code is shown in Table 3.

3.1. Effect of Modification Methods on Water Absorption of WSFs. The magnitude of water absorbency is dictated by the level of water absorption. The test results of water absorption of WSFs before and after modifications are shown in Figure 2.

For unmodified MS1, the value of water absorption is as high as $583.2 \%$ due to a large concentration of polar groups of hydrophilic hydroxyls (-OH) on its surface. And the values of spraying-modified MS2, MS3, and MS4, at $62.2 \%$, $30.2 \%$, and $6.1 \%$, are lower than those of unmodified counterparts. For impregnation-modified MS5 and MS6, the values of $143.3 \%$ and $240.6 \%$ are higher than those of unmodified WSFs, respectively. MS2 has the lowest value. This is mainly because a layer of $\mathrm{Na}_{2} \mathrm{O} \cdot \mathrm{nSiO}_{2}$ wrapped on the surface of WSFs reacts with $\mathrm{CO}_{2}$ in the air to form silicic acid gel, which gradually dries and hardens. The hardening rate accelerates while drying. Silica gel might plug pores and form a layer of hard shell on wheat straw fiber surfaces which would increase the surface density and reduce water absorption (refer to the below reaction formula in (3)).

$$
\mathrm{Na}_{2} \mathrm{O} \cdot n \mathrm{SiO}_{2}+\mathrm{CO}_{2}+m \mathrm{H}_{2} \mathrm{O}=\mathrm{Na}_{2} \mathrm{CO}_{3}+n \mathrm{SiO}_{2} \cdot m \mathrm{H}_{2} \mathrm{O}
$$

MS3 has a low value of water absorption since modifying acrylic emulsion is composed of microparticles adhering to the surface of porous materials with an excellent filmforming property. With excellent hydrolysis and alkali resistance, formed film could effectively reduce the water absorption of WSFs. The water absorption of MS4 is lower than that of MS1 since silicone emulsion here is watersoluble with $40 \%$ active content. As a mixture of particles of different sizes, active constituents could fill various pores and demonstrate excellent profiles of spreadability with long-term hydrophobicity. Thus, it is ideal for permeable waterproof treatment of surfaces with porous structure. After water modification, inorganic salts, sugars, alkaloids, tannin, pigments, and polysaccharides (e.g. mucus, starch, 
TABLE 3: The meanings of test serial number and test code.

\begin{tabular}{lcccccc}
\hline $\begin{array}{l}\text { Method of fiber } \\
\text { treatment }\end{array}$ & $\begin{array}{c}\text { Raw fiber } \\
\text { untreated }\end{array}$ & $\begin{array}{c}\text { Sodium silicate } \\
\text { solution spraying }\end{array}$ & $\begin{array}{c}\text { Pure acrylic polymer } \\
\text { emulsion spraying }\end{array}$ & $\begin{array}{c}\text { Organosilicon waterproof } \\
\text { emulsion spraying }\end{array}$ & $\begin{array}{c}\text { Water } \\
\text { dipping }\end{array}$ & $\begin{array}{c}\text { Lye } \\
\text { dipping }\end{array}$ \\
\hline Serial number & 1 or (a) & 2 or (b) & 3 or (c) & 4 or (d) & 5 or (e) & 6 or (f) \\
\hline
\end{tabular}

Test code: MS, wheat straw fiber water absorption test; MJ, wheat straw fiber crystallinity test; MG, wheat straw fiber FTIR test; MSC, WSFCC water absorption test; MQ, WSFCC mechanical property test.

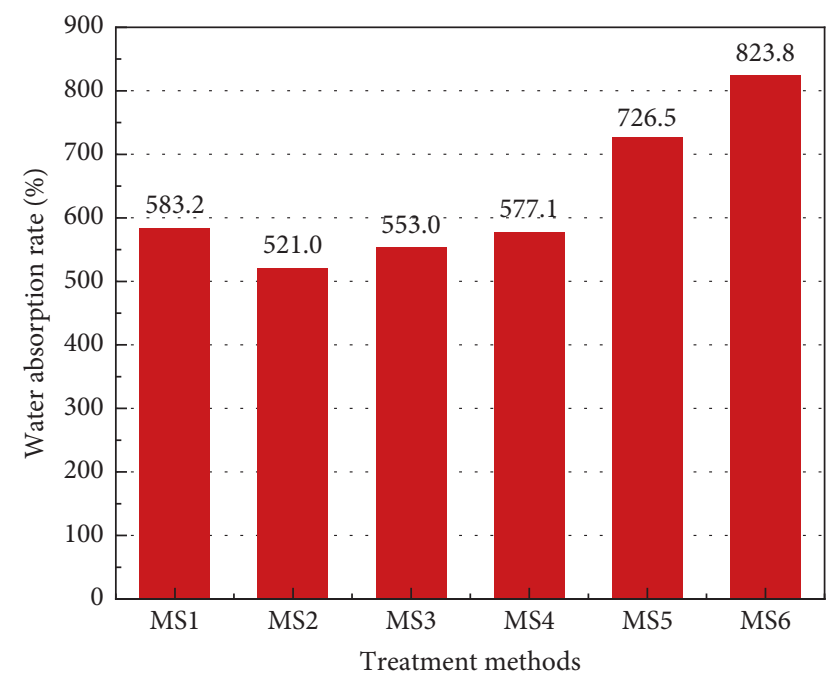

FIGURE 2: Test results of water absorption rate of wheat straw fibers before and after modification.

and pectin) in MS5 are leached away by water. Furthermore, a reduction of esters (wax layer) on its surface causes a partial peeling of original texture [26]. After alkali modification, waxy surface of MS6 becomes partially hydrolyzed into higher fatty acids and alcohols so that greater wettability and higher water absorption ensue. Also, under alkaline conditions, the contents of hemicellulose and lignin will be hydrolyzed and dissolved into resin and glucuronic acid, which can result in loose porous structures [27] and increase MS6 water absorption.

3.2. Effect of Modification Methods on Crystallinity of WSFs. The degree of cellulose crystallinity index (CI) is applied to WSFs to examine the internal structure of the cellulose. CI is defined as the total mass/volume percentage of crystalline in cellulose. CI reflects some inherent properties of cellulose materials. In other words, the higher the crystallinity, the greater the levels of hardness and specific gravity and the lower the degrees of water absorption, swelling, and chemical reactivity. Thus, CI might be used for elucidating the relationship between internal structures and properties of WSFs. XRD spectrogram before and after modifications is shown in Figure 3. The XRD spectrum is fitted by MDI Jade 5.0 software, and CI is calculated according to formula (2). CI obtained is shown in Figure 4 [28-30].

As shown in Figure 3, WSFs are known to contain a large amount of natural cellulose, holocellulose, lignin, and other components (refer to Table 2). Except for few crystalline components with high diffraction intensity and sharp peaks,

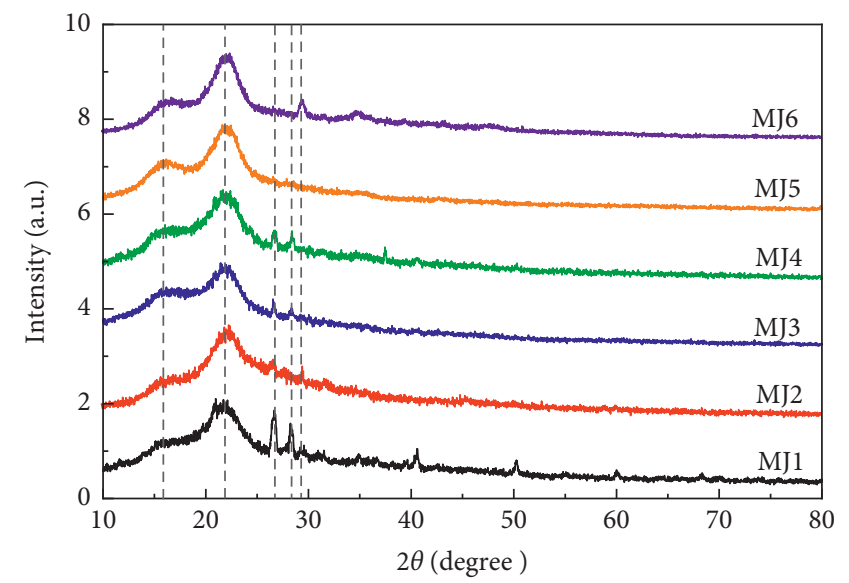

FIgURE 3: XRD spectrogram of wheat straw fibers before and after modification.

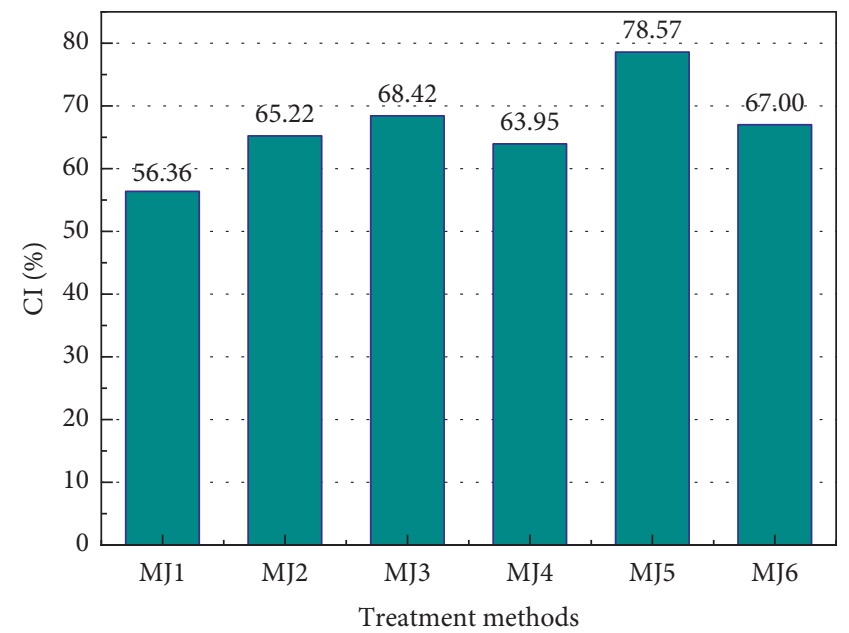

FIgURE 4: Crystallinity of wheat straw fibers before and after modification.

most components have wide and diffuse diffraction peaks with low degree of crystallization. Also, there is no distinct boundary between amorphous and crystalline regions, and the transition zone between them was gradual. The resulting spectrum is basically an amorphous diffraction peak and it belonged to type I spectrum of cellulose.

Figure 4 shows the CI data. As illustrated, the lowest CI is MJ1 (56.36\%), and the highest one is MJ5 (78.57\%). As compared with MJ1, the CIs of several modified WSFs have an increment range of $13.47 \%$ to $39.41 \%$. A higher CI indicates that water absorption of modified fibers is lower than that of unmodified counterparts. The increase in the 
crystallinity of MJ2 is because when $\mathrm{Na}_{2} \mathrm{O} . \mathrm{nSiO}_{2}$ hardens on the fiber surface, it makes some structure of cellulose and hemicellulose more brittle and hard. And a higher CI of MJ3 is correlated with its composition of hard monomers in pure acrylic emulsion covering surface or permeating through internal pores of fibers. As a result, a higher conversion temperature of emulsion glass renders emulsion film more brittle and harder [28]. For MJ4, a higher CI might be explained by $\mathrm{Si}-\mathrm{CH}_{3}$ of silicone emulsion reacting with -OH on cellulose surface to form crystal structures. Regarding impregnation-modified MJ5/MJ6, for removing the anticoagulant components of extracts, hemicellulose and lignin are partially dissolved so that both cellulose content and CI are increased. Regarding the changes of crystalline structure, it indicates that water absorption of MJ5/MJ6 decreases, but because of physical destruction of internal and external structures after removing extracts, water absorption levels of both fibers are higher than those of others (refer to Figure 2).

\subsection{Effect of Modification Methods on Chemical Structure of} WSFs. Water absorbency of WSFs is affected by their chemical structures. The changes of functional groups of WSFs before and after modifications are explored by FTIR (refer to Figure 5) [31-35].

For unmodified MG1, the positions of major absorption peaks and corresponding functional groups are as follows: $3408 \mathrm{~cm}^{-1}$ is the stretching vibration of cellulose intermolecular-associated hydroxyl $(-\mathrm{OH}), 2918 \mathrm{~cm}^{-1}$ is the $\mathrm{C}-\mathrm{H}$ stretching vibration of saturated alkyl groups of cellulose and hemicellulose, $1734 \mathrm{~cm}^{-1}$ is the stretching vibration of $\mathrm{C}=\mathrm{O}$ on acetyl group and carboxyl group in hemicellulose, $1633 \mathrm{~cm}^{-1}$ and $1512 \mathrm{~cm}^{-1}$ are the $\mathrm{C}=\mathrm{C}$ stretching vibration absorption peaks of benzene ring skeleton in lignin, 1250 $\mathrm{cm}^{-1}$ is the C-O stretching vibration in lignin benzene hydroxyl group, $1055 \mathrm{~cm}^{-1}$ is the bending vibration of $-\mathrm{OH}$ and stretching vibration of $\mathrm{C}-\mathrm{O}$ in saccharide cellulose, and $897 \mathrm{~cm}^{-1}$ is the characteristic peak of $\beta-D$ glucoside.

Figure 5 shows some differences between MG1 and MG2. The absorption peak value of MG2 at $3408 \mathrm{~cm}^{-1}$ of MG1 rises slightly. However, the peak shape is narrow, indicating that MG2 fibers close part of the hydroxyl group of cellulose after modification with $\mathrm{Na}_{2} \mathrm{O} \cdot \mathrm{nSiO}_{2}$ and makes their water absorption lower than that of MG1. The absorption peaks of MG2 disappear at the positions corresponding to $1734 \mathrm{~cm}^{-1}$ and $1250 \mathrm{~cm}^{-1}$ of MG1, indicating that the compounds, which are formed through a reaction of Si-O-Si with some ingredients of WSFs, block partially functional groups of hemicellulose and lignin and result in the lower contents of hemicellulose and lignin and the higher crystallinity. This is consistent with the testing results of Figure 4. Also, the peak value of MG2 decreases at the position of $1055 \mathrm{~cm}^{-1}$ of MG1, hinting that the content of polysaccharide and the water absorption are reduced.

In Figure 5, there are some differences among MG3, MG4, and MG1. -OH stretching vibration peaks of MG3 and MG4 at the positions corresponding to $3408 \mathrm{~cm}^{-1}$ of MG1 decrease, indicating a reduction of associated hydroxyl groups. The absorption peak of MG3 at $1734 \mathrm{~cm}^{-1}$ corresponding to MG1

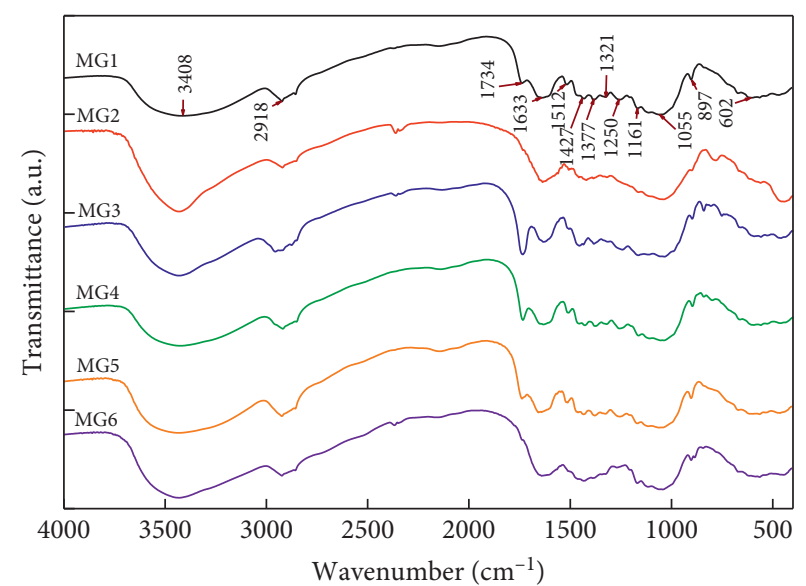

FIgURE 5: FTIR spectrogram of wheat straw fibers before and after modifications.

is a $\mathrm{C}=\mathrm{O}$ characteristic stretching vibration peak from cellulose carboxyl groups. Also, it is due to a $\mathrm{C}=\mathrm{O}$ characteristic stretching vibration peak of pure acrylic polymer. Therefore, the peak value of MG3 at $1734 \mathrm{~cm}^{-1}$ rises markedly. The Si-OC characteristic band in MG4 organosiloxane approximates $1043 \mathrm{~cm}^{-1}$ and it is basically covered by a peak spectrum value at $1055 \mathrm{~cm}^{-1}$. Furthermore, absorption peaks at MG3 and MG4 corresponding to MG1 at $2918 \mathrm{~cm}^{-1}-897 \mathrm{~cm}^{-1}$ are weakened somewhat, indicating that pure acrylic and waterproof emulsions block most functional groups of hemicellulose and lignin, resulting in a relatively lower content of hemicellulose and lignin with a higher crystallinity and a lower water absorption.

Also, in Figure 5, the data of MG5 are compared with MG1. A higher peak value of MG5 at $3408 \mathrm{~cm}^{-1}$ of MG1 indicates that $-\mathrm{OH}$ content is associated with cellulose hydrogen bond and the water absorption of MG5 is increased somewhat after modification. The intensity of most absorption peaks with a MG1 wavenumber under $2918 \mathrm{~cm}^{-1}$ increases in varying degrees, indicating that the contents of hemicellulose and lignin are risen with partial dissolving of some simple carbohydrates. As compared with MG1, MG5 shows that water absorption of water-modified WSFs becomes enhanced through the changes of chemical structures of functional groups. Physically, molecular chains of hemicellulose and lignin and surface pores are damaged with the removal of extracts during water modification. Ultimately, water absorption of fiber is increased and its increment is often greater than that of chemical structure changes.

In Figure 5, the data of MG6 are compared with MG1. The peak value of MG6 becomes narrow and tall at $3408 \mathrm{~cm}^{-1}$. It hints at the increase of $-\mathrm{OH}$ association with cellulose hydrogen bond. It might be due to the actions of $\mathrm{NaOH}$ hydrolyzing waxy surface into fatty acids and alcohols and dissolving partially hemicellulose and lignin. Furthermore, metal hydration ions could enter cellulose, interact with hydrogen bond in cellulose chain, and destroy some crystalline regions so as to increase water absorption. Furthermore, the absorption peaks of MG6 disappear at $1734 \mathrm{~cm}^{-1}$ and $1512 \mathrm{~cm}^{-1}$ of MG1, indicating that the $\mathrm{NaOH}$ 
solution dissolves partially hemicellulose and lignin, depleting their contents, enhancing the crystallinity [36], and ultimately lowering water absorption. As compared with water modifying, with the removal of alkali extracts, the damage caused to hemicellulose and lignin molecular chains is greater than that of the water-modified fibers, and surface pores and defects of the fibers are more exposed (Figure 6). Thus, higher water absorption of physical destruction plays a leading role.

\subsection{Effect of Modification Methods on the Microstructure of} WSFs. Because of the differences in the microstructure of WSFs, the water absorption of WSFs, mechanical properties, and the pore structure of WSFCC change. SEM graphs of WSFs before and after modifications are shown in Figure 6.

As seen from Figure 6(a), both inner and outer surfaces of unmodified WSFs have tilted lamellar substances. Outer epidermis is formed keratinous layer due to mineralization and suppository. The existence of keratinous layer hinders the permeation of slurry and admixture solutions through the outer surface of wheat straw [37, 38] and ultimately affects the bond between WSFs and WSFCCs. Composed of parenchymal cells, inner surface is apt to deform and fracture so that numerous holes and cracks are abundant in cell wall. No keratinous layer exists on inner surface and its roughness is better than that of outer surface. It permits cement slurry and all kinds of admixture solutions to diffuse, permeate, and wet. Overall, water absorption of unmodified WSFs is higher due to the presence of pores and defects on inner and outer surfaces, cell cavity inside fibers, and porous structure formed by gaps between the cells.

Benefits to the treatment are shown in Figures 6(b)-6(d). Most of the open pores and cracks on the surface of the three types of fibers modified by spray coating are blocked by the film layer of the modifier, and the upwarped lamellar brittle substances become the block and rod-shaped bodies integrated with the fibers. Higher surface compactness could impede moisture permeation, obviously reducing water absorption during mixing, improving water and alkali resistance in cement-based materials, facilitating the interfacial effect between fiber surfaces and cement-based materials, and enabling adhesion between fibers and cement-based materials.

As shown in Figures 6(e) and 6(f), the surfaces are damaged. The image shows the increase of surface roughness of chemical-modified fibers, the separation of cell wall bundles, the abscission of some tissues, the formation of many cavities, and the exposure of inner fibers, which was consistent with Vo and Navard's findings [39]. Molecular chains of hemicellulose and lignin are disrupted to some extent during the dissolving of extracts. Also, the inner and outer surfaces are seriously damaged. The inner and outer surfaces of alkali-modified fibers in Figure 6(f) are more damaged than those of watermodified counterparts in Figure 6(e). Fiber bundles are separated and fibers are refined (refer to illustration). With the exposure of numerous pores and defects, water absorption of two impregnation-modified fibers increases significantly.
3.5. Effect of Modification Methods on Water Absorption of WSFCC. Water absorption of WSFCC is shown in Figure 7. Water absorption is correlated with the structure, porosity, and pore characteristics of WSFCC. Under identical material and molding conditions, water absorption of a composite is closely correlated with the water absorption of modified WSFs.

Some notable differences in absorption are evident among the different subjects in Figure 7. Water absorption of WSFCC basically rises with elapsing time and water absorption of each specimen increases rather quickly within $2 \mathrm{~h}$. The specimens with low water absorption are MSC2 and MSC6 at 9.10\% and $10.82 \%$ at $0.5 \mathrm{~h}$, respectively. And those with high water absorption are MSC4 and MSC3 at $31.33 \%$ and $27.01 \%$ at $0.5 \mathrm{~h}$, respectively. After $3 \mathrm{~h}$, the water absorption of specimens gradually slows down. After $5 \mathrm{~h}$, MSC6 has the lowest water absorption, followed by MSC2; the value of water absorption of the two is $23.22 \%$ and $29.34 \%$ at $48 \mathrm{~h}$, respectively, and MSC5 has the highest water absorption, followed by MSC1; the value of water absorption of the two is $41.66 \%$ and $41.01 \%$ at $48 \mathrm{~h}$, respectively. Besides MSC6, the temporal change of water absorption is basically identical to that of WSFs after $5 \mathrm{~h}$. As shown in Figure 2, alkali-modified MS6 has the highest water absorption while alkali-modified WSFCC has the lowest level (Figure 7) because alkaloids hydrolyze esters on the outer surface of WSFs and breach the protection of keratinous layer. The destruction of inner and outer surfaces results in higher water absorption. Also, alkali modification weakens the adhesion between fiber bundles. During drying, the fibers are separated and become smaller and finer. Subsequent vibration molding enables more uniform compact blending for WSFCC mixture with individual finer fibers. With the decrease of the connecting pore size and porosity, there is the lower water absorption of hardened WSFCC.

\subsection{Effect of Modification Methods on Strength of WSFCC.} The results of flexural and compressive strength tests of unmodified versus modified WSFCC at different ages are shown in Figure 8.

The flexural strength and compressive strength of WSFCC specimens increase with advancing age. Except for MQ4 of silicone waterproof emulsion modified fiber specimen, the other four modified fibers have higher flexural and compressive strength than that of unmodified MQ1. The flexural strength and compressive strength of alkali-modified MQ6 are the highest at both early and late stages and much higher than those of other modified fibers. This result agrees with Taallah and Guettala's studies [40]. The 7-day flexural strength and compressive strength of MQ6 are $1.40 \mathrm{MPa}$ and $2.64 \mathrm{MPa}$, the 28-day flexural and compressive strengths are $1.87 \mathrm{MPa}$ and $3.90 \mathrm{MPa}$, and the 56-day flexural and compressive strengths are $2.43 \mathrm{MPa}$ and $5.31 \mathrm{MPa}$, respectively. The higher strength is shown by $\mathrm{Na}_{2} \mathrm{O} \cdot \mathrm{nSiO}_{2}$ - modified MQ2 and pure acrylic emulsion-modified MQ3. The flexural strength and compressive strength of water-modified MQ5 are also higher than those of MQ1. Except for 28-day flexural strength, the strength of MQ4 is lower than that of MQ1. It indicates that the strengthening effect of MQ4 is unsatisfactory as it is in Sood and Dwivedi's study [41]. 


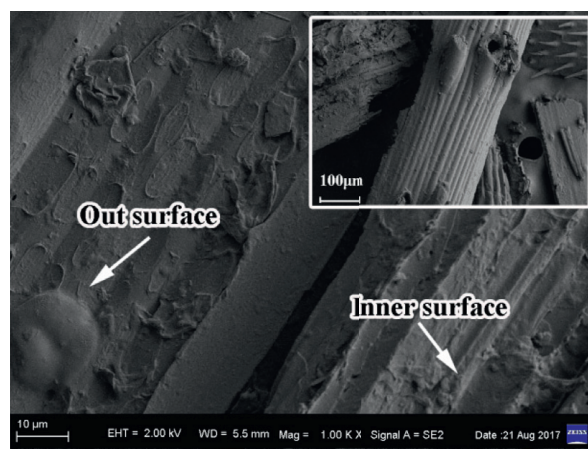

(a)

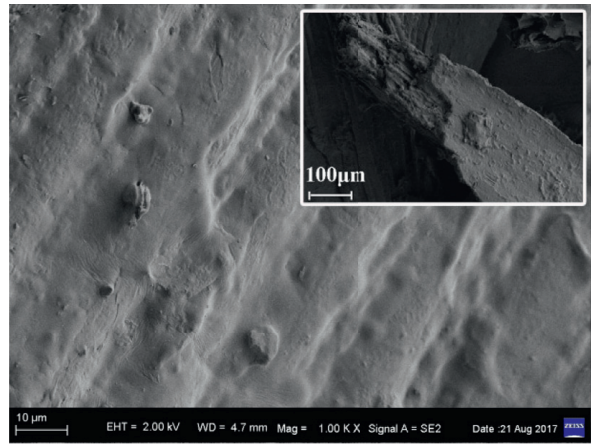

(c)

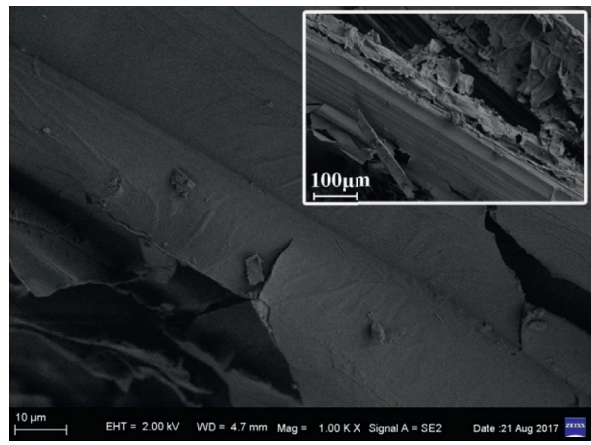

(e)

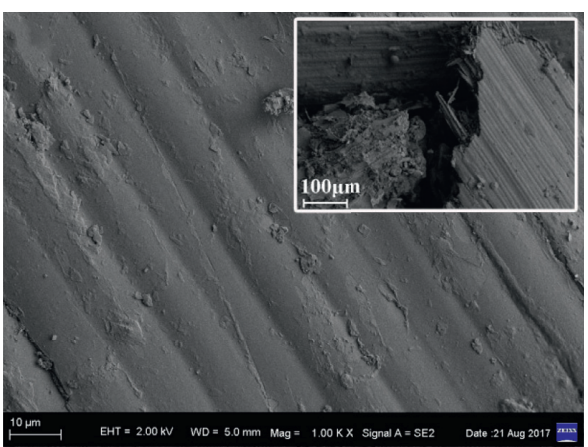

(b)

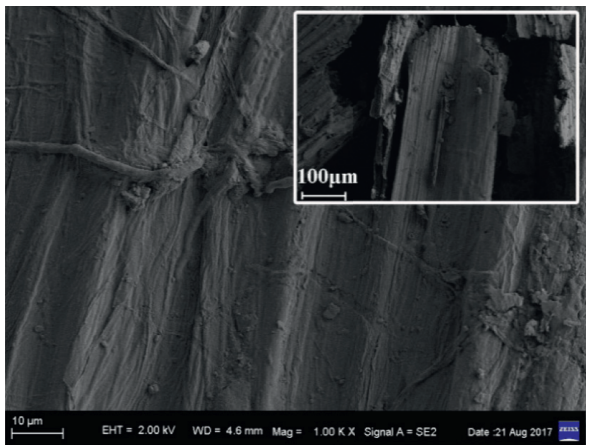

(d)

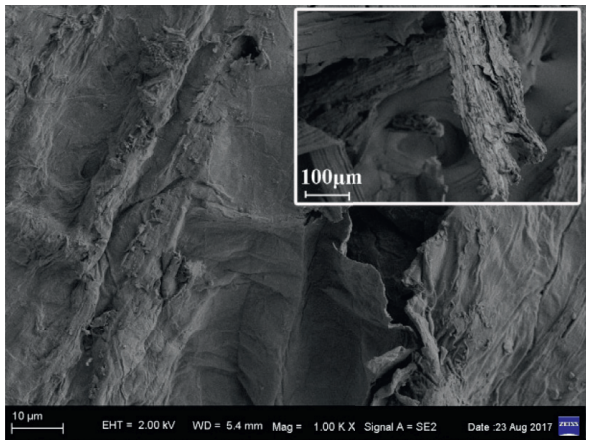

(f)

FIGURE 6: SEM graphs of wheat straw fibers (1000x).

The results in Figure 8 are attributed to water absorption of WSFs and compatibility between WSFs and cement-based materials.

The water absorption of WSF has influence on the flexural strength and compressive strength of WSFCC. The level of water absorption is high for MQ1. At the same consistency, water consumption of WSFCC mixture increases. Upon hardening of cement-based materials, large pores are formed where stagnant water on fiber surface results in lower strength of WSFCC. Also, WSFs with higher water absorption are associated with wet swelling and drying shrinkage. And volume change of WSFs might affect the bond strength between fibers and cement-based materials. Thus, MQ1 does not have a high strength. However, water absorption of MQ2/MQ3 is lower than that of MQ1. So, when keeping the fluidity of WSFCC mixtures basically unchanged, water consumption needed for mixing is less. After WSFCC hardening, the amount of evaporated water or bleeding decreases, the capillary channels and pores formed reduce, the useful cross section of WSFCC to resist load increases, and the bond strength between fibers and cement matrix is enhanced. Thus, the strength of WSFCC is improved.

The compatibility between fiber and cement-based materials also has influence on the flexural strength and compressive strength of WSFCC. The strength of MQ1 is not high because of blocking effect of extracts [42]. The compatibility between fibers and cement-based materials is increased by the coating due to the reduced extraction of MQ2 and MQ3. MQ5 and MQ6 have improved the compatibility between fibers and cement-based materials due to the removal of extracts. For MQ5, removing extracts is not as complete as that of MQ6, so the strength of MQ5 is significantly lower than that of MQ6.

Other influences for an increase of flexural and compressive strength of WSFCC are clear. Except for $28 \mathrm{~d}$ 


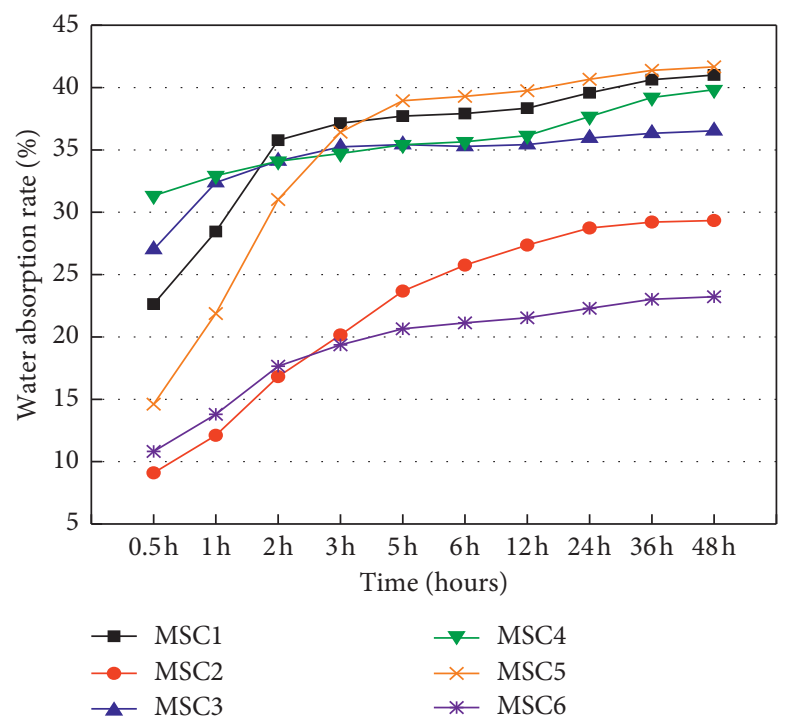

FIGURE 7: Test results of water absorption of WSFCC.

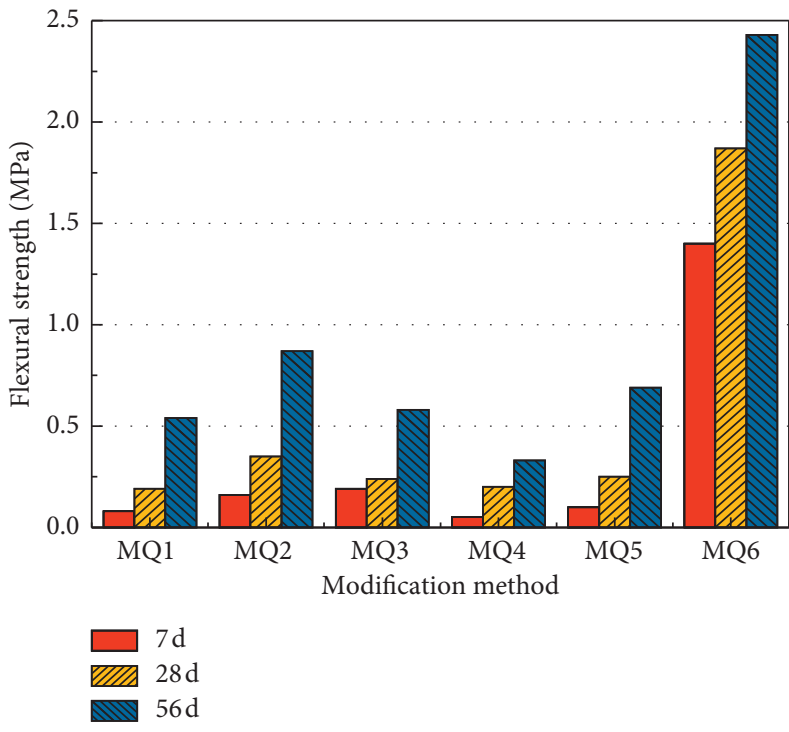

(a)

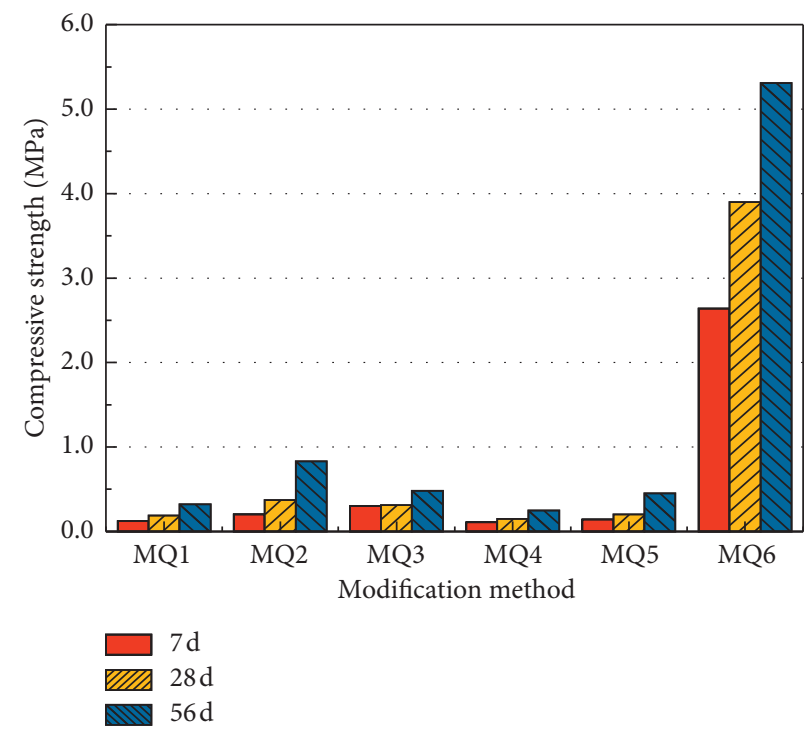

(b)

FIgURE 8: Strength of wheat straw fiber cement-based materials. (a) Flexural strength. (b) Compressive strength.

flexural strength, the strength of MQ4 is lower than that of MQ1. Silane emulsion modifier of WSFs has retarded the hydration reaction of cement-based materials, lowering the compressive strength of WSFCC [43]. In addition, the silane molecular hydrophobic coating decreases water absorption of WSFs during WSFCC mixing. Also, it weakens the bond strength between WSFs and hardens cement-based materials, resulting in lower strength of WSFCC.

In conclusion, the most recommended fiber modification method for obtaining a satisfactory strength of WSFCC is alkali, followed by $\mathrm{Na}_{2} \mathrm{O} \cdot \mathrm{nSiO}_{2}$ and pure acrylic emulsion.

3.7. Effect of Modification Methods on Micromorphology of WSFCC. SEM micromorphological graphs of WSFCC specimens mixing with unmodified or modified WSFs are shown in Figure 9.

As shown in Figure 9(a), the strength of unmodified WSFCC is quite low. The voids between WSFs and cementbased materials are quite large, and interfacial bonding strength is rather poor. They are due to the influence of keratinous surface of unmodified WSFs and wet expansion and drying shrinkage. Dissolving extracts in alkaline solution results in looser structures with numerous pores and cracks.

As seen in Figures 9(b)-9(d), compactness of hydrates and interfacial effects between fiber surface and cementbased materials of three specimens improve greatly as compared with Figure 9(a). Because of the higher surface compactness of sprayed fibers, the release of extracts and the water absorption are reduced. 


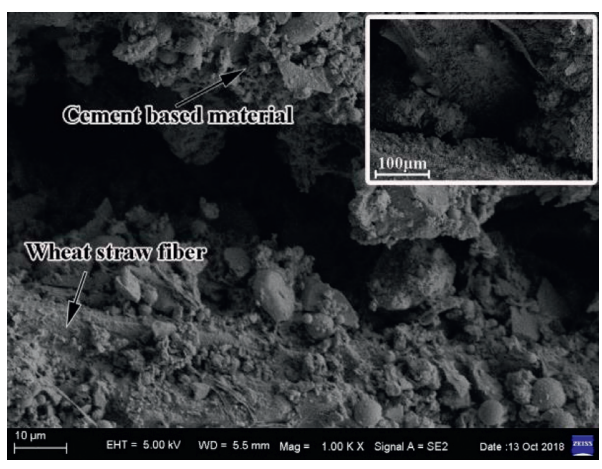

(a)

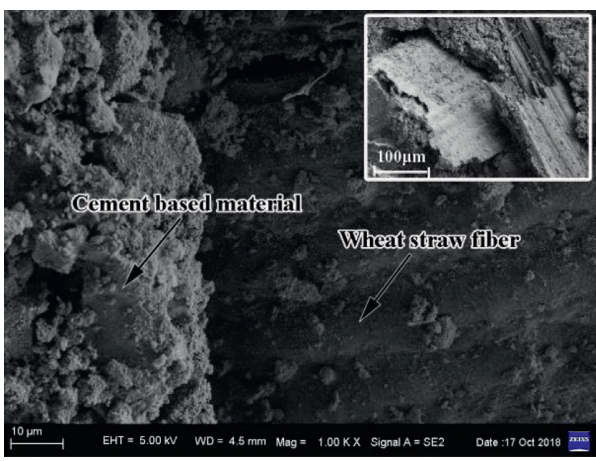

(c)

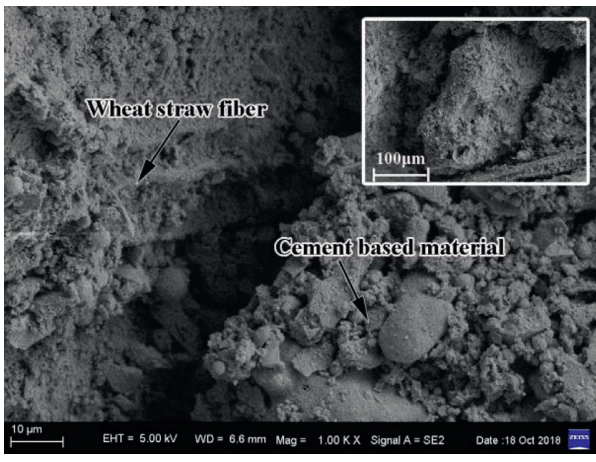

(e)

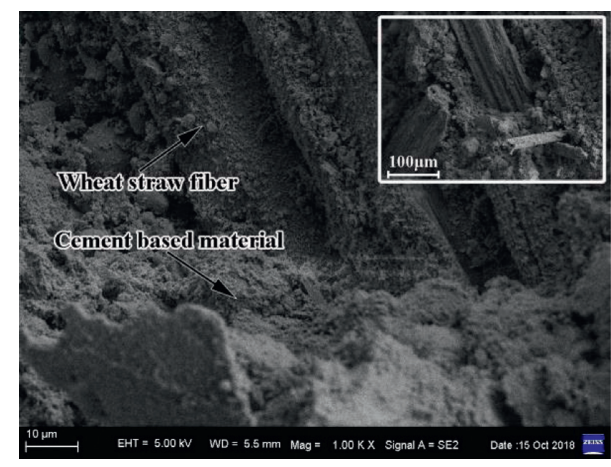

(b)

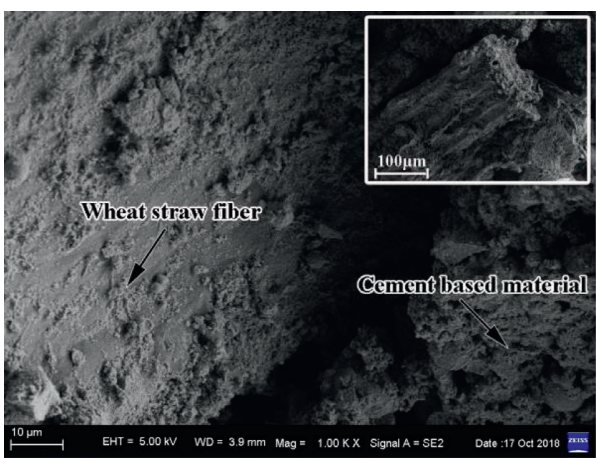

(d)

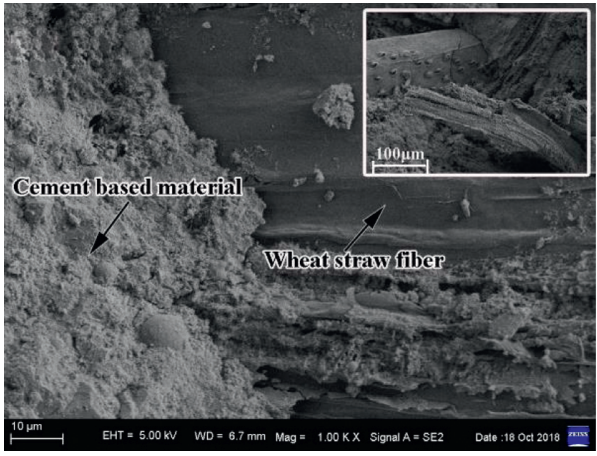

(f)

FIgURE 9: SEM graphs of WSFCC (1000x).

In Figures 9(b) and 9(c), cohesiveness improves obviously between fibers and cement-based materials. Affected by siloxane hydrophobicity of WSFs, as shown in Figure 9(d), interfacial bond strength between fibers and cement-based materials is weakened. Also, the composition of silane emulsion on the fiber surface affects the hydration degree of cement-based materials to a certain extent, so the hydration product has poor integrity and high porosity, and the strength of this specimen is not ideal.

As shown in Figures 9(e) and 9(f), the compactness of hydrates and interfacial bond properties between fibers and cement-based materials improve greatly as compared with Figure 9(a). This is due to weakened anticoagulation of fiber extracts on hydration of cement-based materials and greater surface roughness of water-modified and alkali-modified fibers. Especially in Figure 9(f), due to thorough removal of extracts of alkali-modified WSFs and fining effect of fibers, the compactness of hydrate structure of this specimen is the highest among WSFCC specimens. The interfacial bond is quite strong between fibers and cement-based materials.

In summary, regarding the structure and compactness of hydrates, alkali-modified fiber WSFCC specimens have the best mechanical properties, followed by $\mathrm{Na}_{2} \mathrm{O} \cdot \mathrm{nSiO}_{2}$-modified fiber WSFCC specimens and pure acrylic emulsionmodified fiber WSFCC specimens. It is consistent with the previous findings of Sections 3.5 and 3.6 on water absorption and strength analysis of WSFCC specimens.

3.8. Discussion. In order to further explore the effect of water absorption of WSFs on the mechanical properties of WSFCC, a polynomial fitting curve is established between the water absorption of WSFs (Figure 2) and the strength of WSFCC specimens (Figure 8), as shown in Figure 10. 


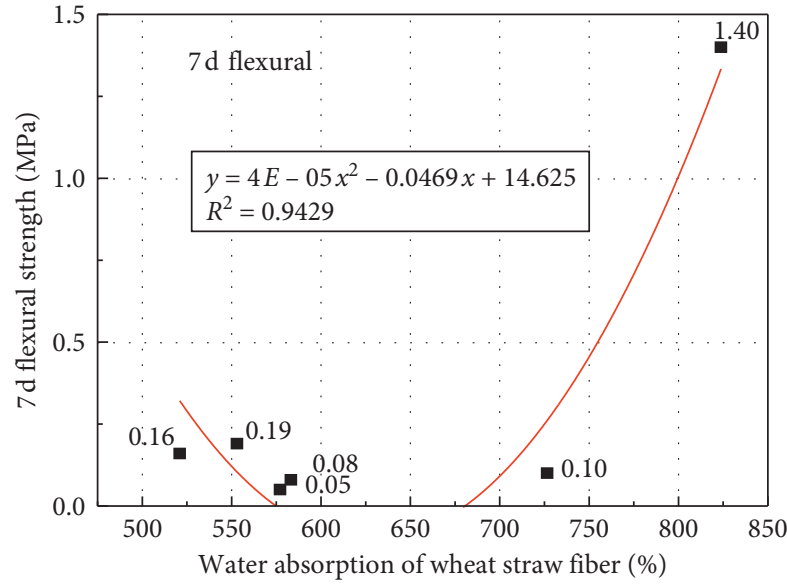

(a)

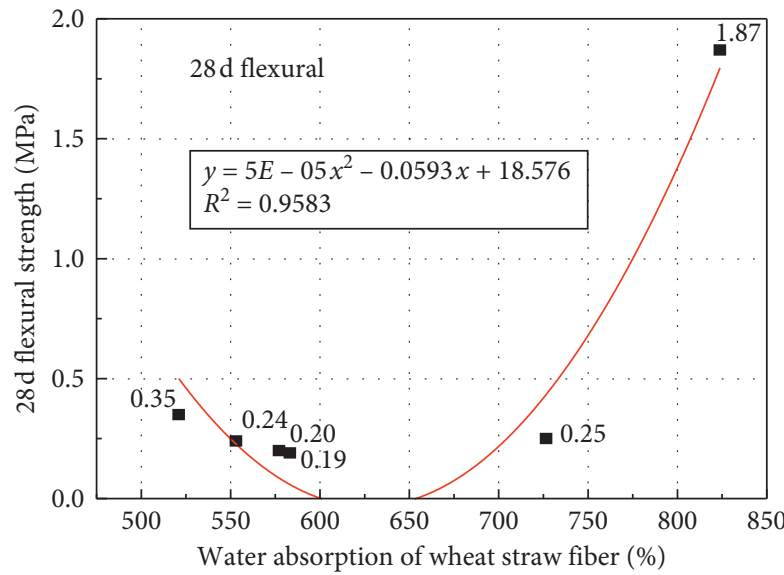

(c)

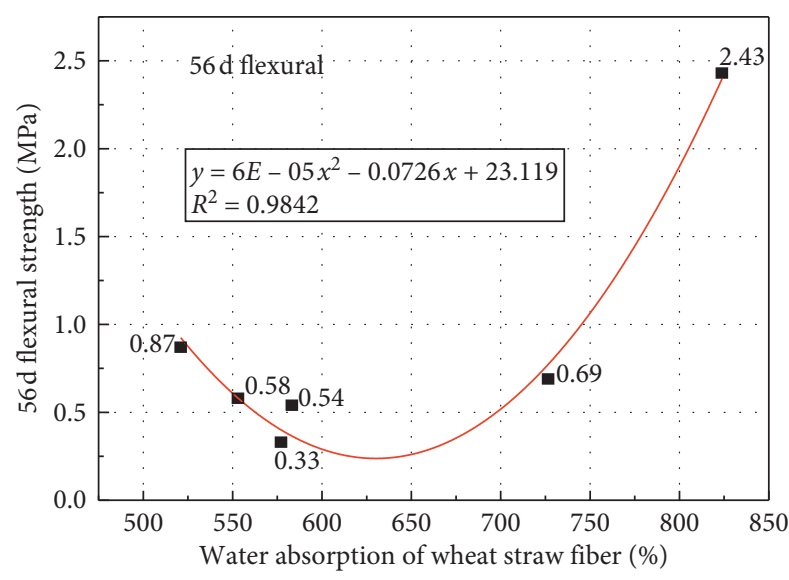

(e)

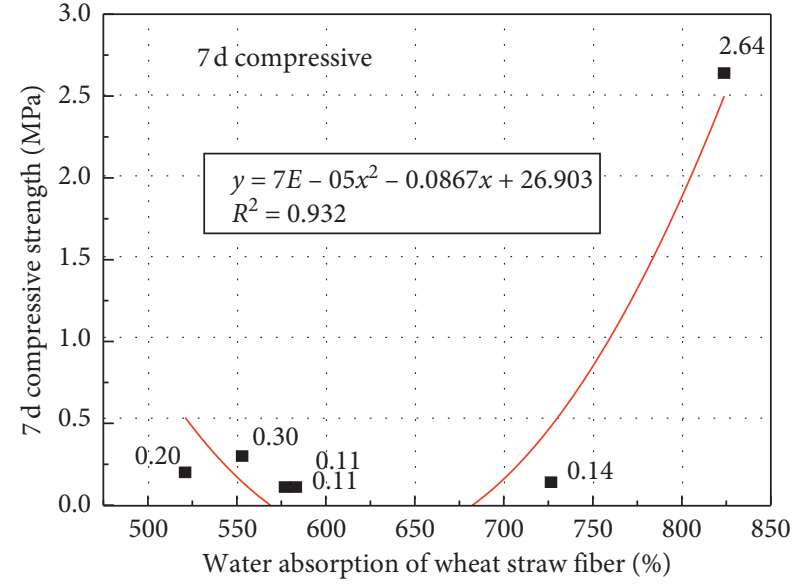

(b)

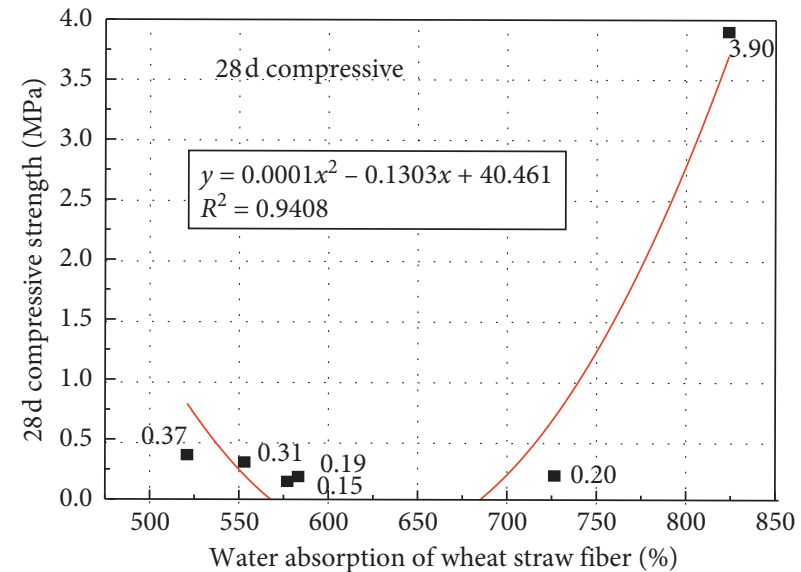

(d)

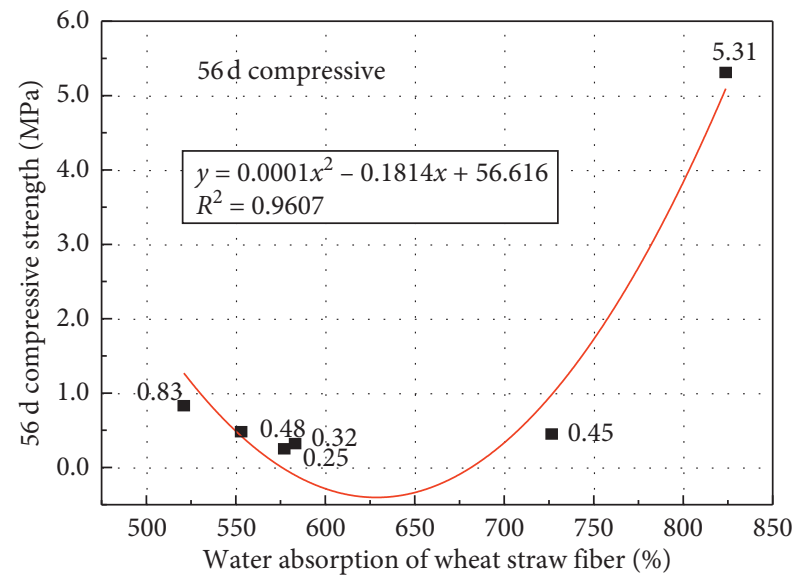

(f)

FIGURE 10: Fitting curves of water absorption of wheat straw fiber versus strength of WSFCC specimen.

The relationship between the water absorption of WSFs and the strength of WSFCC specimens can be found in Figure 10. When the water absorption of wheat straw fiber is less than $630 \%$, this section corresponds to the water absorption of the WSFs modified by untreated and physical methods. The strength of WSFCC decreases with the increase of water absorption of WSF. This is related to the extra water used in the WSFCC mixtures to reach the same consistency because of the fibers absorbing more water. Also, the fibers modified by the spraying methods would inevitably dissolve the extracts in the alkaline hydration solution of cement and have a certain retarding effect on cement. When the water absorption of WSFs exceeds $630 \%$, this section corresponds to the water absorption of wheat 
straw fiber modified by the chemical impregnation method. The strength of WSFCC increases with the increase of water absorption of WSFs, which indicates WSF with high water absorption also has a favorable side to the physical and mechanical properties of WSFCC. It is mainly attributed to extract removing, fiber refining, and surface roughening after impregnation, as well as to the contribution of fiber "internal curing" to the strength of the specimens. The straw fibers with high water absorption release the water absorbed by the fiber body during the hydration process of the cement-based material in the later stage. Because of this, the cement-based material is fully hydrated; the hydration product is increased; the drying shrinkage of specimens is reduced; the strength of WSFCC is increased to some extent [44-46].

As indicated in Figure 10, regression coefficient $R^{2}$ increases with advancing age of WSFCC specimen (specimen strength increases). Also, $R^{2}$ of all three ages of $7 \mathrm{~d}, 28 \mathrm{~d}$, and $56 \mathrm{~d}$ surpasses 0.93 . This indicates that with higher specimen strength, there is a greater fitting accuracy between water absorption of WSFs and WSFCC specimen strength, and both are closely related. Thus, the strength of WSFCC specimens at different ages may be estimated from water absorption of WSFs under the premise of considering the modification method. This fitting formula may offer a theoretical and practical guide for the large-scale development and application of WSFCC.

\section{Conclusion}

The water absorption, crystallinity, chemical structures, and micromorphology of WSFs before and after modifications are analyzed. Water absorption, mechanical properties, and micromorphology of WSFCC specimens are characterized. The effects of WSF modification methods on water absorption and mechanical properties of WSFCCs are expounded from various angles. The major points are summarized as follows:

(1) Water absorption of water/alkali-modified WSFs is $143.3 \%$ and $240.6 \%$ higher than that of unmodified counterparts, respectively. After modifying the WSFs with sodium silicate solution, pure acrylic emulsion, and silicone waterproof emulsion, water absorption of WSFs is $62.2 \%, 30.2 \%$, and $6.1 \%$ lower than that of unmodified counterparts, respectively.

(2) Crystallinity of unmodified WSF is the lowest at $56.36 \%$. As compared with unmodified counterparts, modified WSF demonstrates an incremental range of crystallinity from $13.47 \%$ to $39.41 \%$.

(3) Water absorption of the three WSFs modified with spraying declines largely through reducing $-\mathrm{OH}$ bonding with cellulose, increasing the crystallinity of the fibers or increasing the compactness of the fiber surface. Due to greater association of - $\mathrm{OH}$ hydrogen bond of cellulose and damaged chains of hemicellulose and lignin, bundle structure of cell wall becomes loosened, tissue destruction occurs, and more pores and defects are formed on the surface of two
WSFs modified by impregnation. Thus, there is significantly higher water absorption of the fibers modified by chemical methods.

(4) Except for alkali-modified WSFCC specimens, change pattern in water absorption of other modified WSFCC specimens after $5 \mathrm{~h}$ is basically identical to that of WSFs.

(5) The optimal modifying method for greater strength of WSFCC in a decreasing order is alkali, $\mathrm{Na}_{2} \mathrm{O} \cdot \mathrm{n}$ $\mathrm{SiO}_{2}$, and pure acrylic emulsion.

(6) As for modification methods, an excellent correlation exists between water absorption of WSFs and strength of WSFCC specimens.

\section{Data Availability}

The data used to support the findings of this study are available from the corresponding author upon request.

\section{Conflicts of Interest}

There are no conflicts of interest regarding the publication of this article.

\section{Acknowledgments}

The authors gratefully acknowledged financial supports from Beijing Natural Science Foundation of China (Project No. 2172021), National Natural Science Foundation of China (Project No. 41772335), 13th Five-Year National Key R\&D Program "Research on Facilities Hazard Monitoring and Landslide Early Warning Standards" (Project No. 2018YFF0213304), National Key R\&D Program (Project No. 2016YFC0701810), and Innovative Engineering-Integration and Demonstration: Key Technology R\&D Projects for Improving the Resilience Capability of Urban Rail Transit Infrastructure Disasters (Project No. 2018-1).

\section{References}

[1] M. R. Ahmad, B. Chen, S. Y. Oderji, and M. Mohsan, "Development of a new bio-composite for building insulation and structural purpose using corn stalk and magnesium phosphate cement," Energy and Buildings, vol. 173, no. 8, pp. 719-733, 2018.

[2] H. Li, M. Dai, S. Dai, and X. Dong, "Current status and environment impact of direct straw return in China's cropland-a review," Ecotoxicology and Environmental Safety, vol. 159, no. 15, pp. 293-300, 2018.

[3] H. Liu, X. Ou, J. Yuan, and X. Yan, "Experience of producing natural gas from corn straw in China resources," Resources, Conservation and Recycling, vol. 135, pp. 216-224, 2018.

[4] X. Jia, X. Gan, F. Wang, and Z. Li, "Opportunities and challenges for bioelectricity in rural China," Energy Procedia, vol. 50, pp. 171-177, 2014.

[5] W. Chen, F. Wu, and J. Zhang, "Potential production of nonfood biofuels in China," Renewable Energy, vol. 85, pp. 939944, 2016.

[6] R. R. Romasanta, B. O. Sander, Y. K. Gaihre et al., "How does burning of rice straw affect $\mathrm{CH}_{4}$ and $\mathrm{N}_{2} \mathrm{O}$ emissions? A comparative experiment of different on-field straw 
management practices," Agriculture, Ecosystems \& Environment, vol. 239, pp. 143-153, 2017.

[7] Y. Zhang, G.-Q. Zang, Z.-H. Tang, X.-H. Chen, and Y.-S. Yu, "Burning straw, air pollution, and respiratory infections in China," American Journal of Infection Control, vol. 42, no. 7, p. 815, 2014.

[8] A. Korjenic, J. Zach, and J. Hroudová, "The use of insulating materials based on natural fibers in combination with plant facades in building constructions," Energy and Buildings, vol. 116, pp. 45-58, 2016.

[9] V. M. John, M. A. Cincotto, C. Sjöström, V. Agopyan, and C. T. A. Oliveira, "Durability of slag mortar reinforced with coconut fibre," Cement and Concrete Composites, vol. 27, no. 5, pp. 565-574, 2005.

[10] X.-Y. Zhou, F. Zheng, H.-G. Li, and C.-L. Lu, "An environment-friendly thermal insulation material from cotton stalk fibers," Energy and Buildings, vol. 42, no. 7, pp. 1070-1074, 2010.

[11] J. Ren, Z. Zhao, J. Zhang et al., "Study on the hygrothermal properties of a Chinese solar greenhouse with a straw block north wall," Energy and Buildings, vol. 193, pp. 127-138, 2019.

[12] M. Bederina, B. Belhadj, M. S. Ammari et al., "Improvement of the properties of a sand concrete containing barley strawstreatment of the barley straws," Construction and Building Materials, vol. 115, pp. 464-477, 2016.

[13] S. Hou, F. Liu, S. Wang, and H. Bian, "Coupled heat and moisture transfer in hollow concrete block wall filled with compressed straw bricks," Energy and Buildings, vol. 135, pp. 74-84, 2017.

[14] M. Ramesh, K. Palanikumar, and K. H. Reddy, "Plant fibre based bio-composites: sustainable and renewable green materials," Renewable and Sustainable Energy Reviews, vol. 79, no. 11, pp. 558-584, 2017.

[15] D. Jiang, S. Cui, F. Xu, and T. Tuo, "Impact of leaf fibre modification methods on compatibility between leaf fibres and cement-based materials," Construction and Building Materials, vol. 94, no. 30, pp. 502-512, 2015.

[16] R. Narendar and K. P. Dasan, "Chemical treatments of coir pith: morphology, chemical composition,thermal and water retention behavior," Composites Part B: Engineering, vol. 56, pp. 770-779, 2014.

[17] S. Chakraborty, S. P. Kundu, A. Roy, B. Adhikari, and S. B. Majumder, "Polymer modified jute fibre as reinforcing agent controlling the physical and mechanical characteristics of cement mortar," Construction and Building Materials, vol. 49, pp. 214-222, 2013.

[18] F. Z. Arrakhiz, M. Elachaby, R. Bouhfid, S. Vaudreuil, M. Essassi, and A. Qaiss, "Mechanical and thermal properties of polypropylene reinforced with Alfa fiber under different chemical treatment," Materials \& Design, vol. 35, pp. 318-322, 2012.

[19] M. J. Ahmed and B. H. Hameed, "Adsorption behavior of salicylic acid on biochar as derived from the thermal pyrolysis of barley straws," Journal of Cleaner Production, vol. 195, no. 10, pp. 1162-1169, 2018.

[20] M. R. Cabral, E. Y. Nakanishi, V. dos Santos et al., "Evaluation of pre-treatment efficiency on sugarcane bagasse fibers for the production of cement composites," Archives of Civil and Mechanical Engineering, vol. 18, no. 4, pp. 1092-1102, 2018.

[21] J. Wei and C. Meyer, "Improving degradation resistance of sisal fiber in concrete through fiber surface treatment," Applied Surface Science, vol. 289, no. 1, pp. 511-523, 2014.

[22] J. Claramunt, M. Ardanuy, J. A. García-Hortal, and R. D. T. Filho, "The hornification of vegetable fibers to improve the durability of cement mortar composites," Cement and Concrete Composites, vol. 33, no. 5, pp. 586-595, 2011.

[23] F. Z. Arrakhiz, M. El Achaby, K. Benmoussa, R. Bouhfid, E. M. Essassi, and A. Qaiss, "Evaluation of mechanical and thermal properties of Pine cone fibers reinforced compatibilized polypropylene," Materials \& Design, vol. 40, pp. 528-535, 2012.

[24] Y. Seki, M. Sarikanat, K. Sever, and C. Durmuşkahya, "Extraction and properties of Ferula communis (chakshir) fibers as novel reinforcement for composites materials," Composites Part B: Engineering, vol. 44, no. 1, pp. 517-523, 2013.

[25] D. Jiang, P. An, S. Cui et al., "Effect of leaf fiber modification methods on mechanical and heat-insulating properties of leaf fiber cement-based composite materials," Journal of Building Engineering, vol. 19, pp. 573-583, 2018.

[26] G. Bousfield, S. Morin, N. Jacquet, and A. Richel, "Extraction and refinement of agricultural plant fibers for composites manufacturing," Comptes Rendus Chimie, vol. 21, no. 9, pp. 897-906, 2018.

[27] Y. Zhou, M. Fan, and L. Chen, "Interface and bonding mechanisms of plant fibre composites: an overview," Composites Part B: Engineering, vol. 101, pp. 31-45, 2016.

[28] T. Xia, H. Huang, G. Wu, E. Sun, X. Jin, and W. Tang, "The characteristic changes of rice straw fibers in anaerobic digestion and its effect on rice straw-reinforced composites," Industrial Crops and Products, vol. 121, no. 10, pp. 73-79, 2018.

[29] X. Xie, G. Gou, X. Wei et al., "Influence of pretreatment of rice straw on hydration of straw fiber filled cement based composites," Construction and Building Materials, vol. 113, pp. 449-455, 2016.

[30] X. Zhang, W. Peng, L. Han, W. Xiao, and X. Liu, "Effects of different pretreatments on compression molding of wheat straw and mechanism analysis," Bioresource Technology, vol. 251, no. 3, pp. 210-217, 2018.

[31] T. Lu, S. Liu, M. Jiang et al., "Effects of modifications of bamboo cellulose fibers on the improved mechanical properties of cellulose reinforced poly (lactic acid) composites," Composites Part B: Engineering, vol. 62, pp. 191-197, 2014.

[32] I. N. Grubeša, B. Markovic, A. Gojevic, and J. Brdaric, "Effect of hemp fibers on fire resistance of concrete," Construction and Building Materials, vol. 184, pp. 473-484, 2018.

[33] A. A. Rajput, Zeshan, and C. Visvanathan, "Effect of thermal pretreatment on chemical composition, physical structure and biogas production kinetics of wheat straw," Journal of Environmental Management, vol. 221, pp. 45-52, 2018.

[34] S. P. Kundu, S. Chakraborty, A. Roy, B. Adhikari, and S. B. Majumder, "Chemically modified jute fibre reinforced non-pressure (NP) concrete pipes with improved mechanical properties," Construction and Building Materials, vol. 37, pp. 841-850, 2012.

[35] M. M. Kabir, H. Wang, K. T. Lau, F. Cardona, and T. Aravinthan, "Mechanical properties of chemically-treated hemp fibre reinforced sandwich composites," Composites Part B: Engineering, vol. 43, no. 2, pp. 159-169, 2012.

[36] T. A. Negawo, Y. Polat, F. N. Buyuknalcaci, A. Kilic, N. Saba, and M. Jawaid, "Mechanical, morphological, structural and dynamic mechanical properties of alkali treated Ensete stem fibers reinforced unsaturated polyester composites," Composite Structures, vol. 207, pp. 589-597, 2019.

[37] S. H. Ghaffar, M. Fan, and B. Vicar, "Interfacial properties with bonding and failure mechanisms of wheat straw node and internode," Composites Part A: Applied Science and Manufacturing, vol. 99, no. 8, pp. 102-112, 2017. 
[38] M. U. Farooqi and M. Ali, "Contribution of plant fibers in improving the behavior and capacity of reinforced concrete for structural applications," Construction and Building Materials, vol. 182, pp. 94-107, 2018.

[39] L. T. T. Vo and P. Navard, "Treatments of plant biomass for cementitious building materials-a review," Construction and Building Materials, vol. 121, pp. 161-176, 2016.

[40] B. Taallah and A. Guettala, "The mechanical and physical properties of compressed earth block stabilized with lime and filled with untreated and alkali-treated date palm fibers," Construction and Building Materials, vol. 104, pp. 52-62, 2016.

[41] M. Sood and G. Dwivedi, "Effect of fiber treatment on flexural properties of natural fiber reinforced composites: a review," Egyptian Journal of Petroleum, vol. 27, no. 4, pp. 775-783, 2018.

[42] D. Sedan, C. Pagnoux, A. Smith, and T. Chotard, "Mechanical properties of hemp fibre reinforced cement: influence of the fibre/matrix interaction," Journal of the European Ceramic Society, vol. 28, no. 1, pp. 183-192, 2008.

[43] X.-M. Kong, H. Liu, Z.-B. Lu, and D.-M. Wang, "The influence of silanes on hydration and strength development of cementitious systems," Cement and Concrete Research, vol. 67, pp. 168-178, 2015.

[44] Q. Zeng, T. Mao, H. Li, and Y. Peng, "Thermally insulating lightweight cement-based composites incorporating glass beads and nano-silica aerogels for sustainably energy-saving buildings," Energy and Buildings, vol. 174, pp. 97-110, 2018.

[45] J. T. Kevern and Q. C. Nowasell, "Internal curing of pervious concrete using lightweight aggregates," Construction and Building Materials, vol. 161, pp. 229-235, 2018.

[46] X. F. Wang, C. Fang, W. Q. Kuang, D. W. Li, N. X. Han, and F. Xing, "Experimental investigation on the compressive strength and shrinkage of concrete with pre-wetted lightweight aggregates," Construction and Building Materials, vol. 155, pp. 867-879, 2017. 